\title{
The Use of Extracorporeal Life Support in a Patient Suffering from Venlafaxine Intoxication. A Case Report
}

\author{
Christoph Marquetand ${ }^{1 *}$, Harald F. Langer ${ }^{1}$, Jan Philipp Klein ${ }^{2}$, Tobias Graf ${ }^{1}$ \\ 1 Department of Cardiology, Angiology and Intensive Care, Medicine Medical Clinic II, University Heart Center Lübeck, \\ Lübeck, Germany \\ 2 Lübeck University, Department of Psychiatry and Psychotherapy, Lübeck, Germany
}

\begin{abstract}
Very few reports exist on serious cardiac complications associated with intake of serotonin-noradrenaline reuptake inhibitors. This paper describes and discusses the case of a patient who ingested a dose of $17.5 \mathrm{~g}$ venlafaxine. She developed a full serotonergic syndrome leading to multi-organ failure, including refractory cardiovascular shock, which was managed by early implantation of an extracorporeal life support (ECLS) system as a bridging strategy. This intervention was successful and resulted in full recovery of the patient.
\end{abstract}

Keywords: ECLS, ECMO, intoxication, venlafaxine, cardiogenic shock

Received: 22 July 2019 / Accepted: 26 February 2020

\section{INTRODUCTION}

Venlafaxine is a serotonin-noradrenaline reuptake inhibitor and is highly effective in the treatment of major depressive disorder [1]. Overdose is associated with numerous life-threatening complications like adrenergic excess. There are numerous case reports of refractory cardiogenic shock and arrhythmias due to ingestion of high amounts of venlafaxine [2-4].

Two pathomechanisms of cardiac output failure have been suggested in venlafaxine intoxication. The first hypothesis is myocardial stunning by excessive adrenergic stimulation [5], similar to the possible pathophysiology of Tako-Tsubo syndrome (TTS). This theory has been supported by findings in animal models [6]. Cardiac function usually fully recovers, although there are also reports of patients with remaining left ventricular dysfunction, possibly caused by catecholamine-induced direct myocardial damage $[7,8]$, through myocytal calcium-leakage [9].

The second hypothesis is myocardial stunning through inhibition of the inward sodium current, which is dependent on the venlafaxine concentration [10], resulting in inhibition of the cardiac action potential.
Therapeutic approaches are usually limited to nonspecific supportive therapy until the adverse effects expire.

In this case report, the early use of ECLS as an ultima ratio approach is described.

\section{CASE REPORT}

A 27-year-old female was admitted to the emergency department of the University Hospital Schleswig-Holstein, Luebeck, Germany after ingestion of an initially unknown dose of delayed-release venlafaxine and a large amount of alcohol several hours before. She suffered from hallucinations, hyperreflexia, mydriasis, trism, opsoclonus and myoclonus, suggestive of the serotonergic syndrome. Initial vital parameters were as follows: body temperature $37.0^{\circ} \mathrm{C}$, blood pressure 115/80 $\mathrm{mmHg}$ and pulse $145 \mathrm{bpm}$.

On admission, an electrocardiogram showed a sinus-tachycardia with prolonged corrected QT-interval (QTc) of 513ms with a standard QRS width. Her bloodalcohol level was $2.32 \%$ and her glucose level was 238 $\mathrm{mg} / \mathrm{dL}$. Additional drug screening tests were negative. 
Symptomatic therapy was established. The patient was given $2000 \mathrm{ml}$ Sterofundin ${ }^{\odot}$ (B. Braun Melsungen AG, Melsungen, Germany) and a total of $12 \mathrm{mg}$ of midazolam (Hameln pharma plus gmbh. Hameln, Germany) both intravenously in the first twelve hours after admission.

She was immediately transferred to the hospital's intensive care unit because of severe intoxication with multiple agents and high risk for hemodynamic failure.

Glucose $200 \mathrm{ml}$ of $20 \%$ glucose solution $\left(\mathrm{G} 20 \%{ }^{\odot}\right.$, B. Braun Melsungen AG, Melsungen, Germany) was administered because of recurring severe hypoglycaemia in the following hours.

The patient's blood pressure steadily declined, and a severe chest wall rigidity with hypoxemia made invasive ventilation necessary 12 hours after admission. For the induction of anaesthesia $5 \mathrm{mg}$ of midazolam (Hameln pharma plus gmbh. Hameln, Germany), 50 $\mu \mathrm{g}$ of sufentanil (Hameln pharma plus gmbh. Hameln, Germany) and $50 \mathrm{mg}$ of rocuronium (Fresenius Kabi Deutschland GmbH, Bad Homburg, Germany) were administered intravenously as a bolus.

Directly after induction of anaesthesia, which was 12 hours after admission, vasopressors, noradrenaline up to $10 \mathrm{mg} / \mathrm{h}$, and dobutamine up to $30 \mathrm{mg} / \mathrm{h}$, were needed to support circulation. The patient developed a progressive lactic acidosis, from $1.8 \mathrm{mmol} / \mathrm{L}$ continuously increasing to $19.1 \mathrm{mmol} / \mathrm{L}$ within five hours after induction of anaesthesia.

Transthoracic echocardiography (TTE) revealed a severe left-ventricular dysfunction with a left ventricular ejection fraction (LVEF) of 10-15\% with global leftventricular hypokinesia thirteen hours after admission.

Due to rapidly progressive hemodynamic instability, veno-arterial extracorporeal life support (ECLS; MAQUET CARDIOHELP ${ }^{\circledast}$ ) in a femoro-femoral configuration with high blood flow was established 17 hours after admission.

Diffuse bleeding aggravated the situation. The patient's INR was 3.6, PTT was $62 \mathrm{~s}$. under heparin therapy, antithrombin III was $28 \%$, fibrinogen levels were $0.4 \mathrm{~g} / \mathrm{L}$ and GOT > $7000 \mathrm{U} / \mathrm{I}$. Hence, acute liver failure with disseminated intravascular coagulation was diagnosed.

Venlafaxine serum concentration was $>720 \mu \mathrm{g} / \mathrm{L}$, as determined by high-performance liquid chromatography and electrospray ionization with tandem mass spectrometry.
Acute kidney failure ensued requiring the initiation of slow low-efficiency dialysis via Shaldon catheter, which was continued for fifteen days.

While the patient was on ECLS treatment, systemic heparin was used to prevent clotting in the ECLS circuit and the dialysis circuit.

After explantation of the ECLS regional calcium citrate anticoagulation was used during dialysis. A continuous intravenous application of $400 \mathrm{IE} / \mathrm{h}$ of unfractionated heparin was given to prevent thrombosis until day fifteen post-admission.

On day four post-admission the patient developed septic shock. Her serum procalcitonin (PCT) levels were $11.6 \mathrm{mmols} / \mathrm{L}$ and her serum lactate $5.6 \mathrm{mmol} / \mathrm{L}$.

Based on these data, a decision was made to increase noradrenaline and fluid replacement.

Ventilation was pressure controlled, and oxygen demand gradually increased. A chest X-ray showed infiltrates, resulting in a diagnosis of ventilator-associated pneumonia being made. Antibiotic therapy was initiated with meropenem for eleven days and vancomycin for six days.

Anisocoria and distorted pupils were recurrently observed. However, cranial imaging provided no explanation, and within 3 days, the pupil abnormalities disappeared.

Unusually high doses of sedative medication with up to $1.2 \mathrm{mg} / \mathrm{kg} / \mathrm{h}$ of midazolam (Hameln pharma plus gmbh. Hameln, Germany) and $0.8 \mu \mathrm{g} / \mathrm{kg} / \mathrm{h}$ of sufentanil (Hameln pharma plus gmbh. Hameln, Germany) were needed, most probably because of a sequestration in the ECLS circuit.

Two-dimensional echocardiogram showed a gradually recovering left ventricular function with a LVEF of $45 \%$ on day seven and a LVEF of $55 \%$ on day 21 .

ECLS was weaned on day seven post-admission, and the patient was extubated on day fourteen post-admission at which time the pneumonia had sufficiently improved. She was immediately oriented and showed no signs of neurological damage apart from a clinically apparent lesion of the $\mathrm{N}$. peroneus.

She was transferred to a general ward and later to rehabilitation.

\section{DISCUSSION}

This case demonstrates numerous aspects of venlafaxine intoxication. The management of this condition re- 
mains challenging, especially when the drug overdose has been ingested many hours before or at an uncertain point of time prior to admission to a hospital.

Peak blood levels of drug concentration are usually expected 2-3 hours after ingestion [11]. Cardiac symptoms of venlafaxine intoxication are typically arrhythmias, prolonged QT-interval, tachycardia and hypotension. Reduction of the right and left ventricular systolic function has been hypothesized as caused by similar mechanisms as in TTS [12,13] as well as cardioplegia due to inhibition of the inward sodium current [10]. In our patient cardiac function fully recovered contrary to other reports of patients with a remaining reduction of LV-function, most likely to catecholamine-induced direct myocardial damage $[7,8]$. Hepatotoxicity of venlafaxine is infrequent and caused by direct cell damage [14], in association with high drug doses [15].

Hypotension is usually not responsive to fluid administration [3], thus requiring high doses of catecholamines, usually for several days. The latter is disadvantageous since serious side-effects of prolonged vasopressor-therapy may occur, and the appearance of TTS in venlafaxine intoxications may be linked to the already existing catecholamine-excess. ECLS is a well-established alternative to giving these enormous vasopressor-dosages. Using ECLS might be mandatory in severe cases of venlafaxine intoxication. A threshold for life-threatening toxicity cannot be given, but there are several reports of fatalities after ingestion of about $6 \mathrm{~g}$ of venlafaxine [16]. To our knowledge, two other reports successfully used ECLS following venlafaxine intoxications with $18.5 \mathrm{~g}$ and $20 \mathrm{~g}$ of venlafaxine $[2,4$.] No case reports of survival of such extreme intoxications without ECLS have been identified in the literature.

There is no specific antidote to treat venlafaxine intoxication [17]. Due to the large volume of distribution, venlafaxine cannot be eliminated via haemodialysis. Drug-elimination as early as possible is essential, especially since the drug-metabolism is saturable [18] and prolonged, especially when kidney or liver function is impaired. There are reports of successful drug-elimination with Cytosorb ${ }^{\otimes}$ filters and infusion of intravenous lipid emulsion [2] as well as reports of the use of cyproheptadine [4]. This may be a promising approach in the early stages of the intoxication or after ingestion of the extended-release form of venlafaxine. However, clinical benefits remain unclear. Cardiac arrhythmias often occur with QT-interval prolongation, and they are among the main reasons for high lethality. Lidocaine has been reported as an effective treatment in case of ventricular tachycardia in venlafaxine intoxication [3].

Complications reported in patients receiving lipid emulsions and veno-arterial ECLS support include lipid agglutination and clogging [19,20]. Also, there are reports of fatal outcomes linked to the administration of lipid emulsions in intoxication with lipophilic drugs [21]. Due to recommendations [19], lipid emulsion, as rescue therapy, should be withheld in poisoned patients receiving veno-arterial-ECLS.

Hypoglycaemia and early lactic acidosis could be explained because of the $\beta 2$-adrenoreceptor stimulation and thus augmentation of glycolysis $[22,23]$. Therefore blood glucose levels should be monitored closely.

Neurological symptoms, including seizures, are frequent. In our case, the patient exhibited a severe serotonergic syndrome, which made intubation necessary. Midazolam has been used successfully to treat seizures and perform sedation. High dosages were necessary from the beginning and increased significantly after the establishment of ECLS, most probably due to sequestration of lipophilic drugs, such as midazolam, fentanyl and maybe venlafaxine, in the ECLS-circuit [24]. When dealing with ingestion of the extendedrelease form complications due to a bezoar should be taken into consideration.

\section{CONCLUSION}

In patients with intoxication of a potentially fatal dosage of venlafaxine, cardiogenic shock is often rapidly progressive and refractory. Therefore transferring patients to a hospital with ECLS-standby seems obligatory. Early use of ECLS in progressive shock as a bridge to recovery was shown to be one of the key elements in successful treatment, thus making a full recovery possible.

\section{References.}

1. Cipriani A, Furukawa TA, Salanti G, Chaimani A, Atkinson LZ, Ogawa $Y$, et al. Comparative efficacy and acceptability of 21 antidepressant drugs for the acute treatment of adults with major depressive disorder: a systematic review and network meta-analysis. Lancet 2018;391:1357-66.

2. Schroeder I, Zoller M, Angstwurm M, Kur F, Frey L. Venlafaxine intoxication with development of takotsubo cardiomyopathy: Successful use of extracorporeal life support, intravenous lipid emulsion and CytoSorb ${ }^{\circledR}$. Int J Artif Organs 2017;40:358-60.

3. Mazur JE, Doty JD, Krygiel AS. Fatality Related to a 30-g 
Available online at: www.jccm.ro

Venlafaxine Overdose. Pharmacotherapy 2003;23:1668-72.

4. Thomas A, Ovakim D, Kanji H, Dewar L, Finlayson G. Intravenous Lipid Emulsion Therapy and VA-ECMO rescue therapy for Massive Venlafaxine and Clonazepam Overdose. J Clin Toxicol 2017;07.

5. Vasudev R, Rampal U, Patel H, Patel K, Bikkina M, Shamoon F. Selective Serotonin-norepinephrine Reuptake Inhibitorsinduced Takotsubo Cardiomyopathy. N Am J Med Sci 2016;8:312-5.

6. Ueyama T, Kasamatsu K, Hano T, Yamamoto K, Tsuruo $\mathrm{Y}$, Nishio I. Emotional stress induces transient left ventricular hypocontraction in the rat via activation of cardiac adrenoceptors: a possible animal model of "tako-tsubo" cardiomyopathy. Circ J 2002;66:712-3.

7. Batista M, Dugernier T, Simon M, Haufroid V, Capron A, Fonseca $S$, et al. The spectrum of acute heart failure after venlafaxine overdose. Clin Toxicol 2013;51:92-5.

8. Godkar D, Stensby J, Sinnapunayagam S, Niranjan S. Venlafaxine induced acute myocardial infarction with normal coronary arteries. Am J Ther 2009;16:365-6.

9. Ellison GM, Torella D, Karakikes I, Purushothaman S, Curcio A, Gasparri C, et al. Acute beta-adrenergic overload produces myocyte damage through calcium leakage from the ryanodine receptor 2 but spares cardiac stem cells. J Biol Chem 2007;282:11397-409.

10. Khalifa M, Daleau P, Turgeon J. Mechanism of sodium channel block by venlafaxine in guinea pig ventricular myocytes. J Pharmacol Exp Ther 1999;291:280-4.

11. Fischer M, Unterecker S, Pfuhlmann B. Overdose of Venlafaxine with Mild Outcome. Neurosci Med 2012;03:327-9.

12. Christoph M, Ebner B, Stolte D, Ibrahim K, Kolschmann S, Strasser $\mathrm{RH}$, et al. Broken heart syndrome: Tako Tsubo cardiomyopathy associated with an overdose of the serotonin-norepinephrine reuptake inhibitor Venlafaxine. Eur Neuropsychopharmacol 2010;20:594-7.

13. De Roock S, Beauloye C, De Bauwer I, Vancraynest D, Gurne
The Journal of Critical Care Medicine 2020;6(2) • 123

O, Gerber B, et al. Tako-tsubo syndrome following nortriptyline overdose. Clin Toxicol 2008;46:475-8.

14. Lee WM. Drug-induced hepatotoxicity. N Engl J Med 2003;349:474-85.

15. Christensen RC, Garces LK. Hepatotoxic effects with high-dose venlafaxine. Psychiatry (Edgmont) 2006;3:10-1.

16. Long C, Crifasi J, Maginn D, Graham M, Teas S. Comparison of analytical methods in the determination of two venlafaxine fatalities. J Anal Toxicol 1997;21:166-9.

17. EFFEXOR XR (venlafaxine hydrochloride) Overdosage | Pfizer Medical Information - Canada n.d. https://www. pfizermedicalinformation.ca/en-ca/effexor-xr/overdosage\# (accessed January 12, 2020).

18. Perry PJ. Psychotropic drug handbook. Lippincott Williams \& Wilkins; 2007. P. 171.

19. Lee HMD, Archer JRH, Dargan PI, Wood DM. What are the adverse effects associated with the combined use of intravenous lipid emulsion and extracorporeal membrane oxygenation in the poisoned patient? Clin Toxicol 2015;53:145-50.

20. Hayes BD, Gosselin S, Calello DP, Nacca N, Rollins CJ, Abourbih $D$, et al. Systematic review of clinical adverse events reported after acute intravenous lipid emulsion administration. Clin Toxicol (Phila) 2016;54:365-404.

21. Cole JB, Stellpflug SJ, Engebretsen KM. Asystole immediately following intravenous fat emulsion for overdose. J Med Toxicol 2014;10:307-10.

22. Rogatzki MJ, Ferguson BS, Goodwin ML, Gladden LB. Lactate is always the end product of glycolysis. Front Neurosci 2015;9.

23. Eldem I, Kendirli T, Azapağası E, Özdemir G, Yıldız Ç, Yılmaz MM, et al. Venlafaxine intoxication in an adolescent presenting with severe lactic acidosis. Turk J Pediatr 2016;58:200-2.

24. Shekar K, Roberts JA, Mcdonald Cl, Fisquet S, Barnett AG, Mullany D V., et al. Sequestration of drugs in the circuit may lead to therapeutic failure during extracorporeal membrane oxygenation. Crit Care 2012;16. 